\title{
Disassembly Line Scheduling with Genetic Algorithms
}

\author{
Luminiţa Duţă, Florin Gheorghe Filip, Jean-Michel Henrioud, Ciprian Popescu
}

\begin{abstract}
Disassembly is part of the demanufacturing and it is meant to obtain components and materials from end-of-life products. An essential performance objective of a disassembly process is the benefits it brings, that is the revenue brought by the retrieved parts and material, diminished by the cost of their retrieval operations. A decision must be taken to balance an automatic disassembly line. A well balanced line will decrease the cost of disassembly operations. An evolutionary (genetic) algorithm is used to deal with the multi-criteria optimization problem of the disassembly scheduling.
\end{abstract}

Keywords: control, scheduling algorithms, evolutionary programming, genetic algorithms

\section{Introduction}

In the second half of the $20^{\text {th }}$ century, the people and governments started to become aware that the "take - make - waste" system, which resulted from the industrial revolution, is not sustainable. The assumptions on infinite material "sources" of raw materials and "sinks" to absorbe industrial and domestic wastes could not hold any longer because of the exponential growth of world population and accelerated widespreding of industry and consumption.

In their inspiring book on system engineering, Blanchard and Fabrycky [1, p.555] state that "Green manufacturing should be an objective adopted by producers to reduce the environmental impact of their products and production operation continuously. Real environmental improvement requires a system life-cycle approach to guide design decisions and operational policies". Several driving factors such as: a) competitive differentiation, b) customer consciousness, c) legal regulations, and d) fight for improving profitability have led to this new way of thinking and even to new standards such as ISO 14,000 series.

A new science of sustainability called "Industrial Ecology" was born [2,Frasch ], [3, Graedel, Allenby]. Within it, research directions such as "design for environment" (with a proactive character), and "environmental management" (a reactive, remedial aproach) compose a new design trend called "environmentally conscious design and manufacturing" [1, Blanchard and Fabrycky, p. 558].

At present, both designers and manufacturers show an increasing tendency to consider product and system entire life-cycle starting with perceiving customers needs, and continuing with design and development, manufacturing, product utilization, maintenance, phase-out, and disposal. In this context, the term "remanufacturing" includes the set of planning and processing activities (such as checking in, disassembling, cleaning, inspection and sorting, reconditioning, reassembling, testing and packaging) for recycling obsolete products. The first steps of remanufacturing process can be grouped under the name "demanufacturing". A new industry for demanufacturing has shown up to provide with new usage of expensive modules, components and materials and, at the same time, to prevent excessive wastes. Also industrial producers tend to add their demanufacturing departments to existing manufacturing facilities. Sometimes, chains of firms show up to implement new paradigms such as "extended", "networked", and "virtual" enterprise [3, Filip, Bărbat].

This paper aims at proposing the usage of genetic algorithms for optimal scheduling of disassembly lines. The remaining part of this paper is organised as it follows. First, the main concepts and research directions in modelling, optimization and control in disassembly processes are reviewed. Then, the optimal scheduling problem of a disassembly line is formulated. A short description of genetic algorithms is given next. Experimental results on solving the optimal disassembly problem by a genetic algorithm are given before presenting the paper conclusions. 


\section{Disassembly- A Main Stage in Recycling}

Several types of recycling of end-of-life manufactured goods are possible such as : a) reusing of components and modules of high value, b) refurbishing and partial reconstruction of a good returned from the market, c) recovery of the raw material or energy by incineration and melting. Disposal, which is the last solution to resort to, is done only if the other alternatives are not possible. The choice between these different types determines the recycling process and allow for defining the end-of-life destinations for components of manufactured goods.

Different recycling loops are different approaches of the process. The simplest approach is that of dismantling a product. By applying dismantling operations, a discarded good can be broken down faster and with small costs. In this case more pure fractions can be obtained with less efforts. This simple approach exploits only the value of the raw material. It does not take into account the functional value of the product or of its components.

The regain of the functional values needs a recycling process that minimizes the destroying effects on the product. This means to reuse, refurbish and capitalize the components of the used product in order to remanufacture a new one. Remanufacturing is a superior form of reusing, since its objective is to maximize the value of repaired parts and to minimize the disposal quantity. Central to remanufacturing is the disassembly process that decomposes a product into parts and/or subassemblies. Disassembling is a nondestructive technique and implies the extraction of the desired components and/or materials. If the parts are not reusable after reconditioning, partial or total destructive operations are to be applied: drilling, cutting, wrenching, and shearing. These techniques are used in view of the material or energetically recovery.

There are several research directions in relation with disassembly processes such as: modeling, planning, and control. The chapter 16 on "design for produceability and disposability" of the book on system engineering of Blanchard and Fabrycky [1] contains an excellent introduction to product and system design to facilitate remanufacturing.

Since disassembly processes can be viewed as discrete, event - driven systems [5, Cassandras, Lafortune], Petri nets can be a natural solution. There are lots of reported results. For example, Moore, Gungor and Gupta [6] propose Disassembly Petri nets to take into account operation precedence constraints in planning aplications. Penev and Ron [7] proposed Disassembly graphs. Kuo, Zhang and Huang [8] describe Disassembly trees which associate for each branch the direction of the disassembly operation by adapting the Assembly trees proposed by Henrioud [9]. The usage of object oriented Petri nets proposed by Lakos [10], to model disassembly processes is analysed by Duta, Filip and Henrioud [11].

For balancing the operation of the disassembly line, Duta, Filip and Henrioud [12] utilize the method of equal piles approach proposed Rekiek [13]. To model products associated with incomplete, imprecise, and, sometimes, wrong information, Fuzzy reasoning Petri nets are proposed by Gao and Zhou [14] to make real-time disassembly scheduling decisions possible.

A review of state-of-art implementations of control structures for disassembly line is given by Duta and Filip [15].

\section{Problem formulation}

Disassembly of manufactured products induces both disassembly costs and revenues from the parts saved by the process. Thus, at the planning stage a good trade-off has to be found that depends, both on the "depth" of the disassembly, and on the sequence of operations. The optimization of the ratio between gain and cost can be accomplished by using an appropriate distribution of the disassembly tasks on workstations, an assignment that provides a maximal value for the total profit. The optimization problem depends upon the structure of the disassembly system: if it is made up of a single workstation, the costs depend mainly upon the process duration. If the system is a line, the costs depend mainly 
upon the line balancing, all the more if it is highly manual. Another problem that occurs during a disassembly process is how deep the disassembly sequence must go so as to maximize the outcome of this process. In [11, Duta, Filip and Henrioud], [16, Duta, Henrioud and Caciula] it was shown that an incomplete disassembly sequence can be more profitable than a complete one. Destructive and dismantling operations have to be taken into consideration, as well.

Hence, we have to deal with a multi-criteria optimization problem of a disassembly process: maximizing the benefit it brings deciding how deep the disassembly sequence can go and minimizing the costs using an optimal scheduling along the line. A decision in a scheduling problem upon many criteria is a NP-hard to solve problem [17, Filip]. Stochastic algorithms have already been used to fulfill a multi-criteria optimization problem in [18, Minzu and Henrioud].

In this paper we consider that the line structure was given and propose an algorithm which will allow finding a disassembly sequence and its assignment on workstations that optimizes a very simple function which integrates the income from the parts and the cycle time of the disassembly line.

In this paper we address the case of disassembly lines where the cycle-time is not merely the sum of all operative and logistic times but it also depends strongly upon the line balancing. The objective is to find the most profitable disassembly sequence taking into account, on one hand - the end-of-life options for each part or subassembly of a given product, and on the other hand - the operational times for a given assignment of the tasks on the disassembly workstations.

A cost function which combines both disassembly costs and revenues was proposed in [19, Duta, Filip and Henrioud].

$$
f=\frac{r}{t_{c y}}
$$

where $r$ is revenue associated to each disassembled part and $t_{c y}$ is the cycle time.

The global revenue is the sum of partial revenues obtained according to the end-of-life destinations of the disassembled parts. These partial revenues are established by experts after repeated disassembly processes.

$$
r=\sum_{k} r_{k}, k=\overline{1 . . n c}
$$

where $n c$ is the number of final components or the number of subassemblies obtained after the disassembly process.

The cycle time can be defined like the operational time of the slowest workstation on the line

$$
t_{c y}=\max _{W_{i}} \sum_{j \in\left(\text { tasks on } W_{i}\right)} t_{j}
$$

where $W_{i}$ is the workstation $i$, and $j$ is one disassembly operation and $t_{j}$ the operational times.

We make the following assumptions:

- The disassembly line is linear (flow-shop type);

- End-of-life revenues of the subassemblies are known;

- Operational costs are included in the final incomes;

- The criterion of maximizing the outcome depending of the success rate of disassembly operations has been taken into consideration;

- The failure of the disassembly process is an event that can also occur since certain parts of the product could be deformed and impossible to separate without destroying; 
- The disassembly line is not starving; it works in a continuous flow.

Evaluating the function from equation (1) reveals the profit on a time unit, which is an important indicator for the productivity of the disassembly system. This function also takes into account the value of the cycle time obtained for a well-balanced line. The optimization can be made both for the manual and automatic disassembly lines.

\section{Genetic algorithms}

Genetic algorithms are optimization solvers used in many areas due to their capacity to reduce the combinatorial complexity of NP-complete problems. They do not give the global optimal solution, but a local optimal one by exploiting a defined search space. A genetic algorithm starts with a set of randomly generated possible solutions called initial population. Each member of a population is encoded as a chromosome. Chromosomes are represented by a combination of numbers or characters which contain information about the solution. A score named fitness coefficient is assigned to each chromosome based on the viability of the solution. Chromosomes with high scores are chosen as parents to create a new population. The objective is to obtain children with better scores. To avoid the uniformity of the population and to increase the space of research, at each step of creation, two processes may occur namely: crossover and mutation. Crossover combines the features of two or more parents into one child chromosome. Mutation generates a child similar with his parent with one or more genes altered. These operations ensure the diversity of the new generated population [ 20, Goldenberg].

Once established the initial population and defined the three types of operations (reproduction, crossover, mutation), a genetic algorithm provides new members of population until a stop condition is fulfilled. Usually, this criterion is given by a maximal/minimal value of the objective function obtained after a number of iterations of the genetic algorithm.

\section{Example}

To test the genetic algorithm, consider the example of the disassembly of a Motorola radio set described by Salomonski and Zussman, [21]. The corresponding Disassembly Petri Net is given in the figure 1.

The disassembly process is represented four distinct possible sequences of transitions:

$\left\{t_{1} \rightarrow t_{3} \rightarrow t_{5} \rightarrow t_{7}\right\},\left\{t_{1} \rightarrow t_{3} \rightarrow t_{6} \rightarrow t_{8}\right\},\left\{t_{2} \rightarrow t_{4} \rightarrow t_{5} \rightarrow t_{7}\right\}$ and $\left\{t_{2} \rightarrow t_{4} \rightarrow t_{6} \rightarrow t_{8}\right\}$.

To take into account additional destructive disassembly methods, in the correspondent Petri Net there are three alternative tasks represented by transitions $\left\{t_{1,1}, t_{4,1}, t_{6,1}\right\}$.

For the present study we considered that there are three workstations on the line. An alternative destructive task is done only on a station that can perform both destructive and non-destructive operations. We say that this kind of workstation is a "mixed" one. Thus, workstations 2 and 3 are considered mixed. In other words, when a task is moved from one station to another, the type of the operation is changed together with its operational time.

We supposed that the tasks $t_{1}$ and $t_{4}$ can be performed in a non-destructive way on the first workstation and in a destructive way on the second one. For the task $t_{6}$ a destructive disassembly is done on the third station and a non-destructive disassembly is performed on the second workstation.

According to the Petri Net given in figure 1 the correspondent operational times on the initial partition of the tasks on the workstations are:

$$
T_{i}=\{0.92,0.07,0.07,0.12,0.95,0.75,0.75,0.95\}
$$

Taking into consideration the times for the alternative destructive operations the set above becomes: 


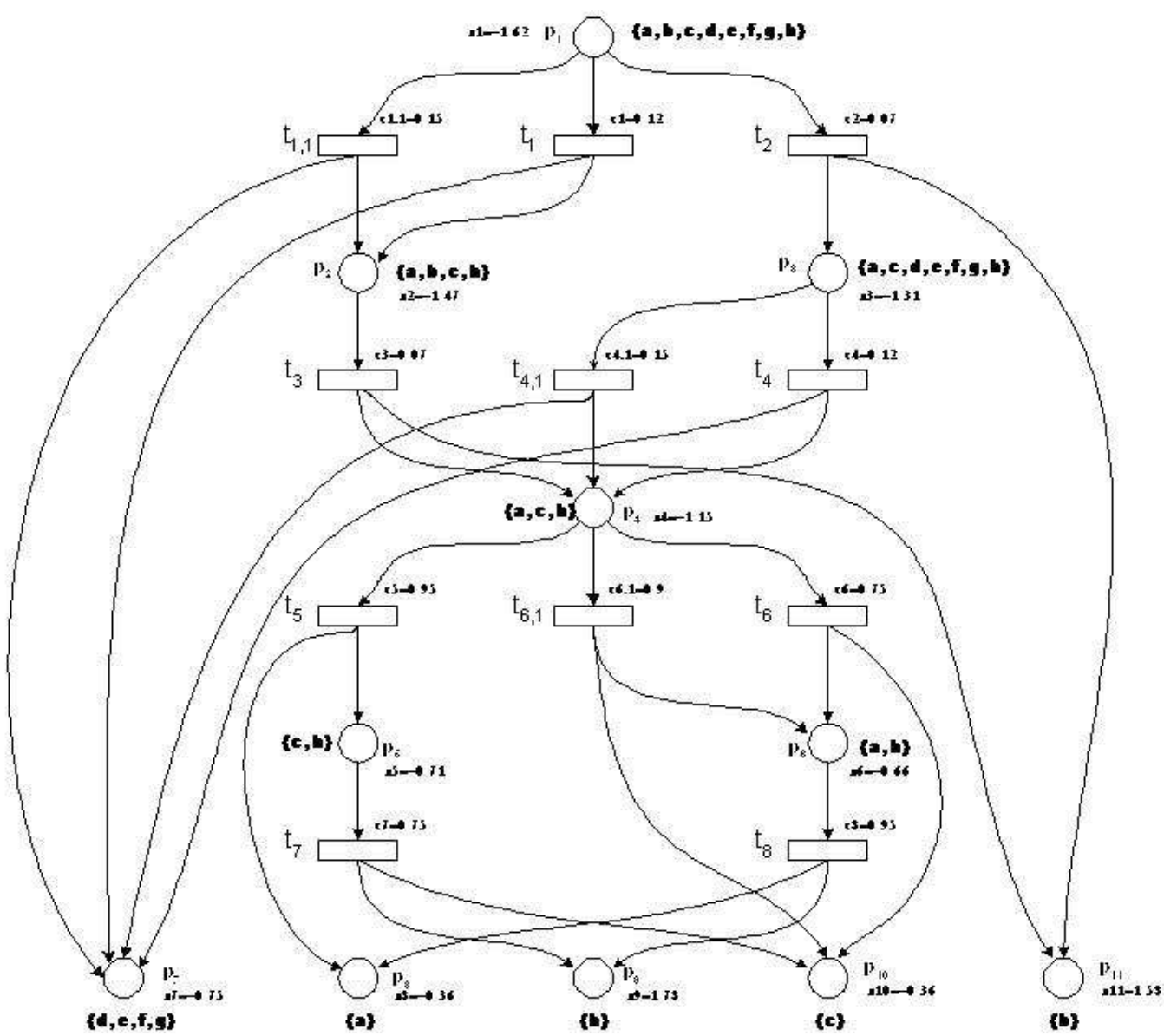

Figure 1: Disassembly Petri Net of a radio set

$$
T_{f}=\{0.95,0.07,0.07,0.15,0.95,0.90,0.75,0.95\}
$$

The final revenues are calculated with the method proposed in [11, Duta, Filip and Henrioud] by using the data from the Petri Net given in the figure 1. The corresponding sets of revenue values are:

$$
\begin{aligned}
& R_{i}=\{-1.36,0.27,0.54,0.54,0.62,0.67,2.75,2.75\} \\
& R_{f}=\{-1.32,0.27,0.54,0.50,0.62,0.60,2.75,2.75\}
\end{aligned}
$$

The objective is to maximize the value of the function from the equation (1) by finding the sequence that maximize the final revenue and in the same time ensuring a well-balance of the disassembly line (e.g. minimizing the cycle time).

In our problem, a chromosome is represented by the possible tasks assignment matrix $S$ which elements are:

$$
s_{i j}=\left\{\begin{array}{l}
1 \text { if the task } j \text { can be assigned to the workstation } i \\
0 \text { if the task } j \text { can't be assigned to the workstation } i
\end{array}\right.
$$

$i=\overline{1 . . n}$ and $j=\overline{1 . . m}$ ( $n$ is the number of workstations and $m$ - the number of disassembly operations).

One $S$ matrix can be the solution of our optimization problem only if it satisfies the following constraints:

1. The non-divisibility constraint that does not allow a task to be assigned to more than one station.

$$
s_{i j} \in\{0,1\}
$$


2. The assignment constraint that it requires that each task be assigned to exactly one station.

$$
\sum_{i} s_{i j}=1
$$

3. The precedence constraint that invokes technological order so that if task $i$ is to be done before task $j(i<j)$, then $i$ cannot be assigned to a station downstream from task $j$

$$
\sum_{k=1}^{n} k \cdot s_{k i}-\sum_{k=1}^{n} k \cdot s_{k j} \leq 0
$$

The steps of the genetic algorithm are:

Step 1 Generating the initial population.

There are three workstations and eight operations (tasks). The matrix of the possible task assignment is:

$$
M=\left(\begin{array}{llllllll}
1 & 1 & 1 & 1 & 0 & 0 & 0 & 0 \\
0 & 0 & 1 & 1 & 1 & 1 & 0 & 0 \\
0 & 0 & 0 & 0 & 1 & 1 & 1 & 1
\end{array}\right)
$$

We generated 24 matrices $S$ that fulfill the constraints (4)- (6) by using the method presented in [19, Duta, Filip, and Henrioud]. We randomly chose three of them as shown bellow:

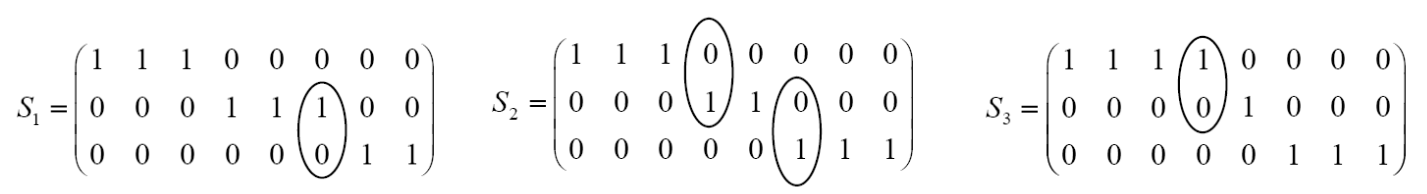

We observe that the three matrices can be obtained by moving an operation from one workstation to the next workstation.

The repartition of tasks on the workstations is represented in the figure 2 .

Step 2 Evaluating by the value of the objective function.

The fitness coefficients $\mathrm{f} 1$ and $\mathrm{f} 2$ are defined by calculating the value of the objective function from the equation (1) for each complete disassembly sequence of the radio set given in the Figure 1.

Table 1: Evaluation of the initial population

\begin{tabular}{cccccc}
\hline & & & fitness & strength & average \\
& $f 1$ & $f 2$ & $(f 1+f 2) / 2$ & fitness \% & \\
\hline$S 1$ & 0.5 & 0.6 & 0.55 & $33 \%$ & 1 \\
$S 2$ & 0.5 & 0.43 & 0.46 & $27 \%$ & 0.80 \\
$S 3$ & 0.75 & 0.6 & 0.675 & $40 \%$ & 1.20 \\
sum & & & 1.685 & $100 \%$ & \\
average & & & 0.5616 & $33 \%$ & \\
\hline
\end{tabular}

\section{Step 3 Selection.}

The selection of the individuals is made after their robustness so as to generate a more robust and healthy population.

We can not utilize the roulette method of selection because it generates non valid individuals (that don't respect the three constraints specified before). Matrices $S_{1}$ and $S_{3}$ are the strongest. 


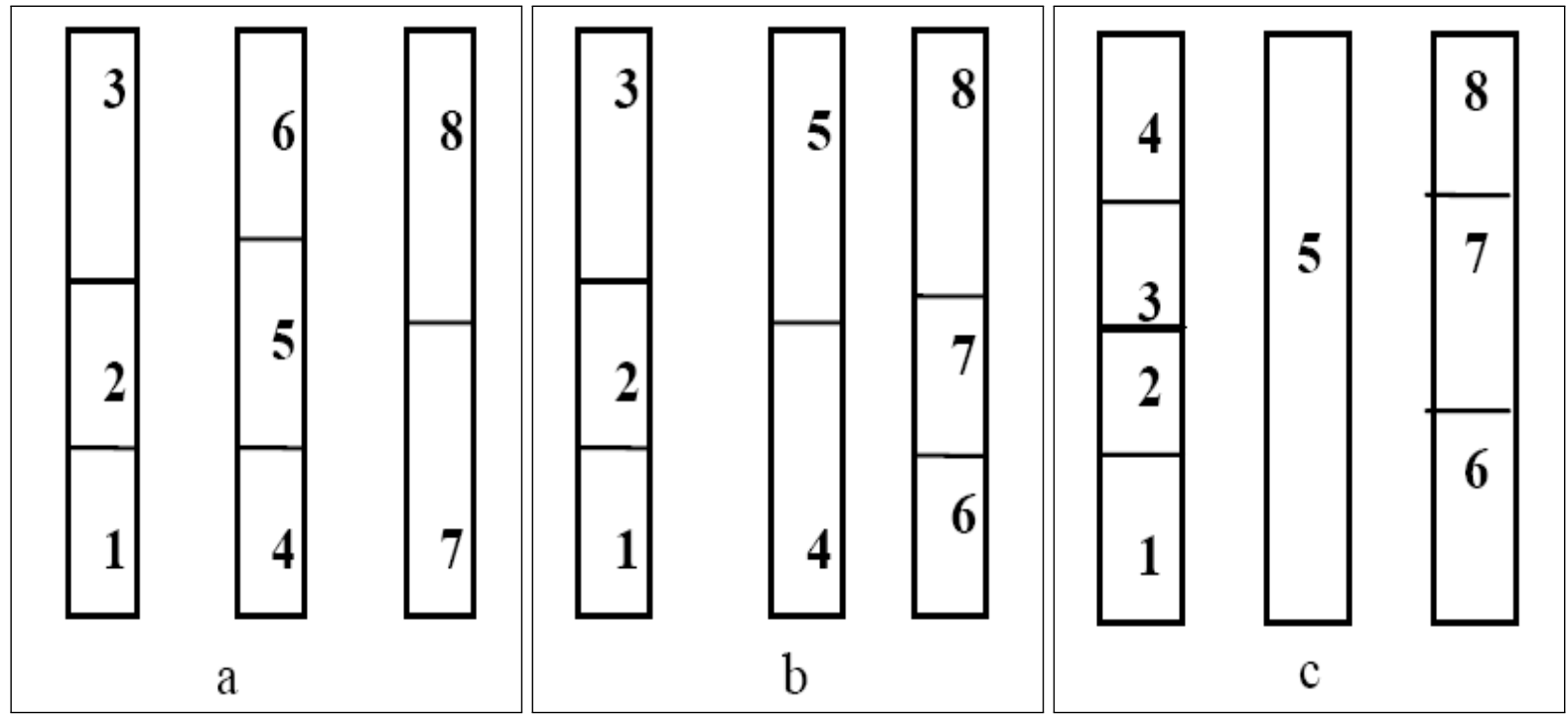

Figure 2: Assignment of tasks on the three stations for the initial population

\section{Step 4 Crossover}

If we have two matrices $\mathrm{A}$ and $\mathrm{B}$ of the same dimensions

$$
\begin{aligned}
& A=\left\{a_{i j}\right\} \quad i=\overline{1 . . n}, j=\overline{1 . . m} \\
& B=\left\{b_{i j}\right\} \quad i=\overline{1 . . n}, j=\overline{1 . . m}
\end{aligned}
$$

The crossover operator $\oplus$ is defined as

$$
a_{i j} \oplus b_{i j}=\left\{\begin{array}{l}
0 \text { if }\left(a_{i j}=0 \text { and } b_{i j}=0\right) \text { or if }\left(a_{i j}=1 \text { and } b_{i j}=1\right) \\
1 \text { if }\left(a_{i j}=1 \text { and } b_{i j}=0\right) \text { or if }\left(a_{i j}=0 \text { and } b_{i j}=1\right)
\end{array}\right.
$$

We also define a special matrix called mask matrix

$$
M S K=\left(\begin{array}{cccccccc}
0 & 0 & 0 & 0 & 0 & 0 & 0 & 0 \\
0 & 0 & 0 & 0 & 0 & 1 & 0 & 0 \\
0 & 0 & 0 & 0 & 0 & 1 & 0 & 0
\end{array}\right)
$$

Calculating $S_{1} \oplus M S K$ and $S_{3} \oplus M S K$ we obtained two chromosomes that have two genes crossed: a new chromosome and a copy of chromosome $S_{2}$ :

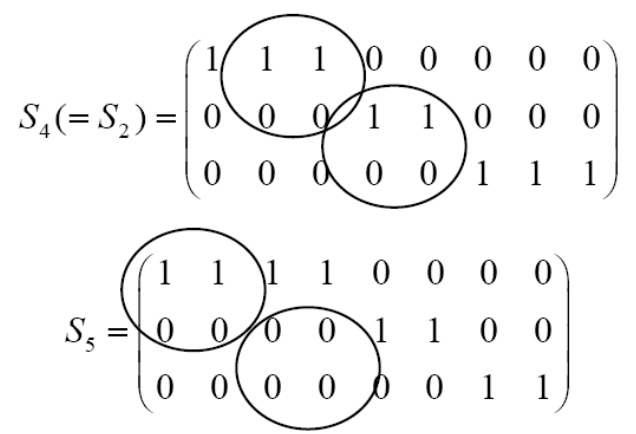

\section{Step 5 Mutation}

A mutation can be made by the movement of one task between two neighboring stations. A new individual is obtained from $S_{4}$ 


$$
S_{5}=\left(\begin{array}{llllllll}
1 & 1 & 1 & 1 & 0 & 0 & 0 & 0 \\
0 & 0 & 0 & 0 \\
0 & 0 & 0 & 0 & 1 & 1 & 1 & 0 \\
0 & 0 & 0 & 1
\end{array}\right)
$$

Step 6 Replacing the initial population

Performances of the new population are represented in the table 2.

Table 2: Evaluation of the new population

\begin{tabular}{cccccc}
\hline & & & fitness & strength & average \\
& $f 1$ & $f 2$ & $(f 1+f 2) / 2$ & fitness \% & \\
\hline S3 & 0.75 & 0.6 & 0.675 & $31 \%$ & 0.92 \\
S5 & 0.95 & 0.75 & 0.85 & $38 \%$ & 1.16 \\
S6 & 0.75 & 0.6 & 0.675 & $31 \%$ & 0.92 \\
sum & & & 2.20 & $100 \%$ & \\
average & & & 0.73 & $33 \%$ & \\
\hline
\end{tabular}

Step 7 Iteration

As a result the genetic algorithm is iterated until a stop condition is accomplished. After 20 iterations the maximal value of the objective function remains 0.95 . So the optimal assignment of tasks is given by the matrix $S_{5}$. The value of the function from the equation (1) is given in euro/second.

\section{Conclusions}

A new computation method in the problem of the optimization of the disassembly sequences is proposed in this paper. The method used has the advantage that it takes into account the operational durations, as well as the profit achieved after a disassembly process from the valorization of the obtained components or subassemblies. In a balanced disassembly line, the cycle time has the lowest value so the operational costs are minimized. The algorithm does not optimize the balance of the disassembly line, but give a solution that improves this balance.

Applying an evolutionary algorithm some undetectable solutions of the problem can be taken into account. However, using genetic algorithms implies a lot of information. The result is obviously faster obtained than using the backtracking method. In the disassembly process a local and fast solution for the optimal disassembly sequence is preferred to the complex and slower algorithms.

In the future work evolutionary programming will be applied to disassembly more complex industrial products.

\section{Acknowledgement}

This work was partially supported from Grant CEEX 13-CEEX F03 of INCE-IEI funded by the National Authority for Scientific Research (ANCS).

\section{Bibliography}

[1] B.S. Blanchard, W.J. Fabrycky, Systems Engineering and Analysis, 4th edition. Prentice Hall, Upper Saddle River, N.J., 2006. 
[2] R.A. Frasch, "Industrial ecology. A Philosophical Introduction". Proc. of NAS 89.

[3] T.E. Graedel, B.R. Allenby, Industrial Ecology. Prentice Hall, Upper Saddele River, N.J, 2003.

[4] F.G. Filip, B.E. Bărbat, Informatica industrialã (Industrial Informatics), Ed. Tehnică, Bucureşti (In Romanian), 1999.

[5] C.G. Cassandras, S. Lafortune. Introduction to Discrete Event Systems. Springer Science, 2008.

[6] K. Moore, A. Gungor, S. Gupta, "Disassembly process planning using Petri Nets". Proceedings of the IEEE International Symposium On Electronics andEnvironment, Oak Brook, Illinois, 1998.

[7] K.D. Penev, A.J. de Ron, Determination of a disassembly strategy International Journal of Production and Research, vol. 34, no. 2, 1996.

[8] T.C. Kuo, H.C. Zhang, S.H. Huang, Disassembly analysis for electromechanical products: a graph based heuristic approach. International Journal of Production Research, vol. 38, no.5, 2000.

[9] J.M. Henrioud J.M, Contribution a la conceptualisation de I'assemblage automatise: nouvelle approche en vue de la determination des processus d'assemblage, These de doctorat, Université de Franche Comté, France, 1989.

[10] C.A. Lakos, From Coloured Petri Nets to Object Petri Nets, Spring Verlag, Vol. 935, 1995.

[11] L. Duţă, F.G. Filip, J.M. Henrioud, "Determination of the optimal disassembly sequence using decision trees”, Intelligent Assembly and Disassembly, ELSEVIER LTD, pp. 43-48, UK, 2003.

[12] L. Duţă, F.G. Filip, J.M. Henrioud, "Applying equal piles approach to disassembly line balancing problem", Proceedings, IFAC World Congress, Prague, 2005.

[13] B. Rekiek, B. Assembly line design. Ph.D. Thesis, University of Brussels.

[14] M. Gao, M.-C. Zhou, "Fuzzy reasoning Petri nets for demanufacturing process design", Proceedings , IEEE Symp. Electronics and the Environment, 2001

[15] L. Duţă, F.G. Filip, "Control and decision-making process en disassembly used electronic products", Studies in Informatics and Control - SIC, vol. 17, no.1, 17-26, 2008.

[16] L. Duţă, J.M. Henrioud,I. Caciula, “A Real Time Solution to Control Disassembly Processes”, Proceedings of the 4th IFAC Conference on Management and Control of Production and Logistics, MCPL '07, p.289-294, Sibiu, September 2007.

[17] F.G. Filip, Sisteme suport pentru decizii (Decision Support Systems), Editura Tehnica, Bucuresti, (in Romanian), 2004.

[18] V. Minzu, J.M. Henrioud, "Stochastic algorithm for tasks assignments in single or mixed-model assembly lines", APII-JESA,vol. 32, no. 7-8, pp. 831-851, 1998.

[19] L. Duţă, F.G. Filip, J.M. Henrioud, "A method for dealing with multi-objective optimization problem of disassembly processes", Proceedings of The IEEE International Symposium of Assembly and Task Planning ISATP03, pp. 163-168, July, France, 2003.

[20] D.E. Goldenberg, Genetic Algorithms in Search, Optimisation and Machine Learning, Adisson Wesley, USA, 1989.

[21] N. Salomonski, E. Zussman, “On-line Predictive Model for Disassembly Process Planning Adaptation”, Robotics and Computer Integrated Manufacturing, vol. 15, pp. 211-220. 


\begin{tabular}{|c|c|}
\hline $\begin{array}{l}\text { Luminiţa Duţă } \\
\text { Valahia State University } \\
\text { utomatics and Computer Science Department }\end{array}$ & \\
\hline Targoviste, Romania & Jean-Michel Henrioud \\
\hline and & Université de Franche Comté \\
\hline $\begin{array}{r}\text { INCE-Centre for economy of } \\
\text { Industry and Services(IEI) } \\
\text { Bucharest, Romania }\end{array}$ & $\begin{array}{l}\text { Besancon, France } \\
\text { E-mail: jean-michel.henrioud@ @univ-fcomte.fr }\end{array}$ \\
\hline E-mail: duta@valahia.ro & $\begin{array}{r}\text { Ciprian Popescu } \\
\text { Valahia State University }\end{array}$ \\
\hline $\begin{array}{r}\text { Florin Gheorghe Filip } \\
\text { The Romanian Academy-INCE } \\
\text { and }\end{array}$ & $\begin{array}{r}\text { Automatics and Computer Science Department } \\
\text { Targoviste, Romania } \\
\text { E-mail: nicoc_ro@yahoo.com }\end{array}$ \\
\hline
\end{tabular}

The National Institute for R\&D in Informatics (ICI)

Bucharest, Romania

E-mail: ffilip@acad.ro

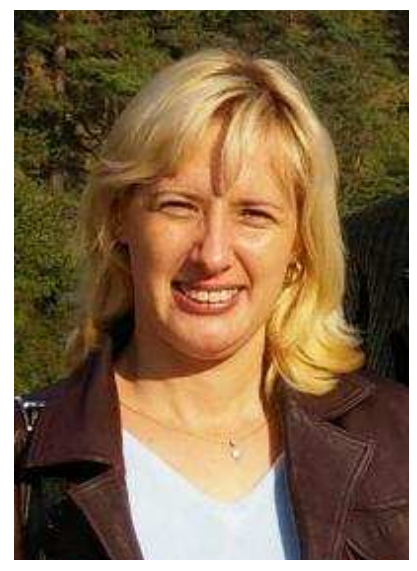

Luminita Duţă took her $\mathrm{PhD}$ in Control Engineering at FrancheComte University, Besançon, France coordinted by Prof. Dr. Jean-Michel Henrioud. She is currently associate professor at Valahia University of Targoviste, Romania, where she is in charge with courses on object oriented programming and automatic control. Her research interests include control evolutionary computation, heuristics and optimization.

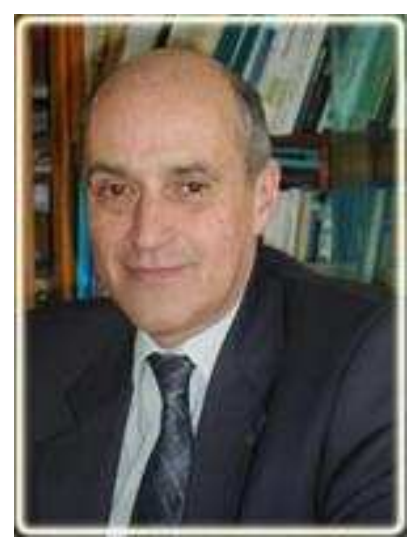

Florin Gheorghe Filip, member of the Romanian Academy (elected in 1991), received his M. Sc and Ph. D. in Control Engineering from the Technical University "Politehnica" Bucharest (PUB) in 1970 and 1982, respectively. He has been with the National R \& D Institute for Informatics (ICI Bucharest) since 1970 and was the managing director of ICI from 1991 to 1997. He was elected in 2000 (and re-elected in 2002 and 2006) as a vice-president of the Romanian Academy. He has been the chair of the technical committee "Large Scale Complex Systems" of IFAC ("International Federation of Automatic Control") since 2002, and the executive president of the "Forum for Information-Knowledge Society" since 1997. His main scientific interests include: control and optimization of large-scale systems, decision support systems, technology management, and models for knowledge-information society. $\mathrm{He}$ is author/co-author of five books, editor of nine volumes and the author/co-author of over two hundred articles published in contributed volumes and scientific journals (http://www.acad.ro/cv2006/birou_vice02Filip.htm). 

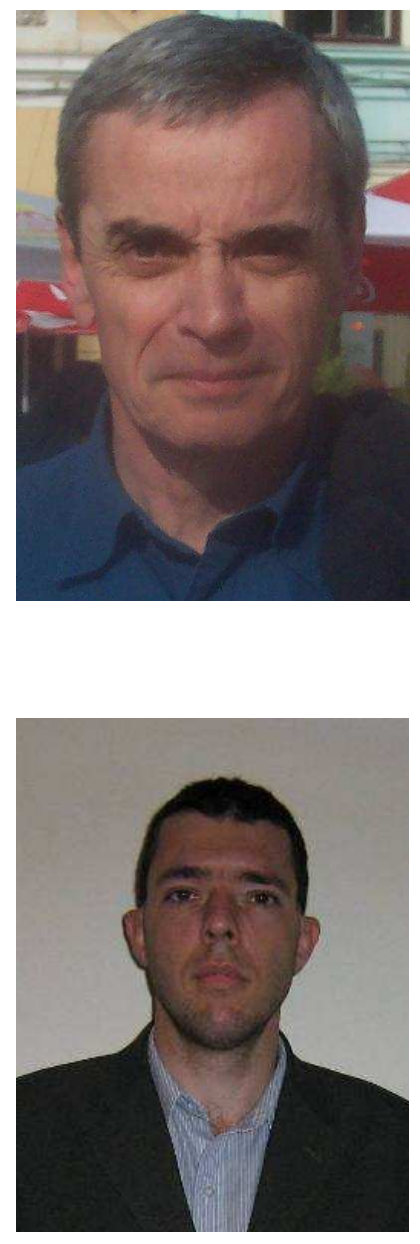

Jean-Michel Henrioud is Full Professor at the University of Franche Comté, Besançon, France. He was the president of the Doctoral Science School for Engineers of the Franche Comté University and the adjoint director of the Automation Laboratory from Besancon. He coordinated more than $30 \mathrm{PhD}$ thesis in assembly and disassembly research fields. Under his coordination important studies in conception, analyze, modeling and control of the production systems, particularly in those of automatic assembly and disassembly processes were done.

Nicolae Ciprian Popescu, (teaching assistant, second degree), received his M. Sc in Modern Systems for Process Control, Information Processing and Transmission from the "Valahia" University of Targoviste in 2004 and Bachelor of Computer Science from the "Politehnica" University of Bucharest (PUB) in 1999. He has more than 8 years practical experience in software development, and 5 years practical experience in teaching at university level. As a Software Engineer of "The Group of Electricity Transmission and Distribution" of Targoviste from 1999 to 2003 he developed software packages for studying the M.V. (medium voltage) and L.V. (low voltage) electric power networks and for the implementation of the electricity billing systems. In 2003 he was accepted in the teaching staff of Automation and Informatics Department, "Valahia" University of Targoviste. His main scientific interests include: decision support systems, environment management and technology management. 